\title{
Iron-Promoted Elimination of $\beta$-Thioalkoxy Alcohols. Olefination by Coupling of a Carbonyl Group with a Dithioacetal
}

\author{
Li-Fu Huang, Chih-Wei Chen, and Tien-Yau Luh* \\ Department of Chemistry, National Taiwan University, Taipei 106, Taiwan \\ tyluh@ntu.edu.tw
}

Received July 5, 2007

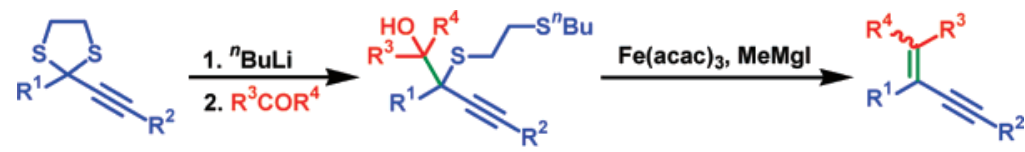

Treatment of propargylic dithiolanes with "BuLi followed by a carbonyl electrophile yields the corresponding propargylic dithioacetals. Upon treatment with 1 equiv of $\mathrm{Fe}(\mathrm{acac})_{3}$ and excess MeMgl, elimination of SR and $\mathrm{OH}$ moieties from 8 affords the corresponding olefins in satisfactory yield. Benzylic dithioacetals behave similarly. The reaction can be considered an alternative of McMurry coupling of two different carbonyl equivalents.

Elimination of two vicinal heteroatom substituents $\mathrm{X}$ and $\mathrm{Y}$ provides a useful regio- and stereoselective protocol for the synthesis of olefins. ${ }^{1-7}$ This kind of transformation would be particularly practical if the heteroatom-substituted starting

(1) (a) Smith, M. B.; March, J. March's Advanced Organic Chemistry: Reactions, Mechanisms and Structure, 6th ed.; Wiley: Hoboken, 2007; pp 1534-1546. (b) Bruckner, R. Advanced Organic Chemistry: Reaction Mechanisms; Harcourt: San Diego, 2002; pp 160-167. (c) Concellón, J. M.; Rodríguez-Solla, H. Chem. Soc. Rev. 2004, 33, 599. (d) Shinokubo, H.; Oshima, K. Synlett 2000, 322.

(2) (a) Percy, J. M. In Comprehensive Organic Functional Group Transformations; Katritzky, A. R., Meth-Cohn, O., Rees, C. W., Eds.; Pergamon: Oxford, 1995; Vol. 1 (Roberts, S. M., Ed.), pp 553-587. (b) Piva, O. In Comprehensive Organic Functional Group Transformations II; Katritzky, A. R., Taylor, R. J. K., Eds.; Pergamon: Oxford, 2005; Vol. 1 (Cossy, J., Ed.), pp 586-600.

(3) Corey, E. J.; Winter, A. E. J. Am. Chem. Soc. 1963, 85, 2677.

(4) For a review, see: Wong, H. N. C.; Fok, C. C. M.; Wong, T. Heterocycles 1987, 26, 1345.

(5) For reviews, see: (a) Maercker, A. Org. React. 1965, 14, 270. (b) Wadsworth, W. S. Org. React. 1977, 25, 73. (c) Maryanoff, B. E.; Reitz, A. B. Chem. Rev. 1989, 89, 863. (d) Shen, Y.-C. Acta Chim. Sin. 2000, 58, 253.

(6) For reviews, see: (a) Peterson, D. J. J. Org. Chem. 1968, 33, 780. (b) Ager, D. J. Org. React. 1990, 38, 1. (c) Barrett, A. G. M.; Hill, J. M.; Wallace, E. M.; Flygare, J. A. Synlett 1991, 764. (d) van Staden, L. F.; Gravestock, D.; Ager, D. J. Chem. Soc. Rev. 2002, 31, 195.

(7) For reviews, see: (a) Kocienski, P. J. In Comprehensive Organic Synthesis; Trost, B. M., Fleming, I., Eds.; Pergamon: Oxford, 1991; Vol. 6 (Winterfeldt, E., Ed.), pp 975-1039. (b) Blakemore, P. R. J. Chem. Soc., Perkin Trans. 1 2002, 2563. materials are readily accessible. Elimination of vicinal dihalides, ${ }^{2}$ Corey-Winter reaction, ${ }^{3}$ and deoxygenation of epoxides ${ }^{4}$ are well-documented. Alternatively, the heteroatom-containing precursors can be generated in situ from the corresponding carbonyl compounds. Wittig and HornerWadsworth-Emmons reactions, ${ }^{5}$ Peterson olefination, ${ }^{6}$ and Kociensky-Julia synthesis of trans-olefins, ${ }^{7}$ inter alia, are typical examples. It is known that a $\beta$-thioalkoxy alcohol can be conveniently obtained from the reaction of a sulfurstabilized carbanion with a carbonyl compound. ${ }^{8}$ Simultaneous elimination of vicinal thioalkoxy and hydroxyl groups leading to the formation of olefin has been sporadically explored. ${ }^{9}$ It is known that a carbon-sulfur bond can be activated by a low valent transition metal catalyst. ${ }^{10}$ Numerous examples on $\beta$-heteroatom elimination of a $\sigma$-metalalkyl complex or intermediate under various conditions are known. ${ }^{11,12}$ We recently reported that activated dithiolanes

(8) For reviews, see: (a) Gröbel, B.-T.; Seebach, D. Synthesis 1977, 357. (b) Page, P. C. B.; van Niel, M. B.; Prodger, J. C. Tetrahedron 1989, 45, 7643. (c) Yus, M.; Nájera, C.; Foubelo, F. Tetrahedron 2003, 59, 6147.

(9) (a) Denis, J. N.; Dumont, W.; Krief, A. Tetrahedron Lett. 1979, 20, 4111. (b) Hoye, T. R.; Kurth, M. J. J. Org. Chem. 1980, 45, 3549. (c) Shimagaki, M.; Shiokawa, M.; Sugai, K.; Teranaka, T.; Nakata, T.; Oishi, T. Tetrahedron Lett. 1988, 29, 659. (d) Chevrie, D.; Lequeux, T.; Pommelet, J.-C. Org. Lett. 1999, 1, 1539.

(10) For a review, see: Luh, T.-Y.; Ni, Z.-J. Synthesis 1990, 89 
undergo ring-opening reactions selectively with an organolithium or organocopper reagent to give the corresponding sulfur-stabilized carbanions which can couple with a range of electrophiles. ${ }^{13,14}$ When propargylic dithoacetals were employed, the reactions have been applied for the synthesis of substituted allenes, ${ }^{15}$ furans, ${ }^{16}$ and pyrroles. ${ }^{16 a}$ It is envisaged that $\beta$-thioalkoxy alcohol may be conveniently synthesized by this transformation when a carbonyl compound is used as the electrophile.

There has been an increasing use of iron catalysts for the activation of $\mathrm{C}-\mathrm{X}$ bonds in organic synthesis. ${ }^{17}$ Iron catalysts are known to promote cross-coupling reactions of vinylic thioethers and thioesters with Grignard reagents ${ }^{18}$ and reduction of carbon-sulfur bonds. ${ }^{10,19} \mathrm{~A} \sigma$-iron-alkyl might be involved. We felt that a $\beta$-heteroatom elimination of such $\sigma$-iron-alkyl intermediate might also take place leading to the formation of olefin. In this paper, we report a new olefination reaction of dithioacetals with carbonyl compounds via the iron-promoted elimination of $\beta$-thioalkoxy alcohols.

Reactions of benzylic dithioacetal 1 with ${ }^{n} \mathrm{BuLi}$ followed by carbonyl compounds afforded the corresponding $\beta$-thioalkoxy alcohols $\mathbf{2}$ in good yield. Treatment of $\mathbf{2}$ with 1 equiv of $\mathrm{Fe}(\mathrm{acac})_{3}$ and 5 equiv of $\mathrm{MeMgI}$ in refluxing toluene for $40-48 \mathrm{~h}$ gave the corresponding olefins 3 in moderate to good yield (eq 1). ${ }^{20}$ Representative examples are summarized in Table 1.

(11) Examples on stoichiometric $\beta$-heteroatom elimination reactions: (a) Rosenblum, M. Pure Appl. Chem. 1984, 56, 129. (b) Daves, G. D., Jr. Acc. Chem. Res. 1990, 23, 201.

(12) Examples on catalytic $\beta$-heteroatom elimination reactions: (a) Henry, P. M. Acc. Chem. Res. 1973, 6, 16. (b) Karabelas, K.; Hallberg, A. J. Org. Chem. 1986, 51, 5286. (c) Shi, X.; Luh, T.-Y. Organometallics 1990, 9, 3019. (d) Ma, S.; Lu, X. J. Chem. Soc., Chem. Commun. 1990, 733. (e) Sen, A.; Lin, M.; Kao, L.-C.; Huston, A. C. J. Am. Chem. Soc. 1992, 114, 6385. (f) Shiu, L.-L.; Yu, C.-C.; Wong, K.-T.; Chen, B.-L.; Cheng, W.-L.; Yuan, T.-M.; Luh, T.-Y. Organometallics 1993, 12, 1018. (g) Ma, S.; Lu, X. J. Org. Chem. 1991, 56, 5120. (h) Zhu, G.; Lu, X. Organometallics 1995, 14, 4899.

(13) (a) Ikehara, H.; Tanimoto, S.; Oida, T. J. Chem. Soc., Perkin Trans. 1 1984, 1223. (b) Krief, A.; Kenda, B.; Barbeaux, P. Tetrahedron Lett. 1991, 32, 2509.

(14) For a recent review, see: Luh, T.-Y.; Lee, C.-F. Eur. J. Org. Chem. 2005, 3875 .

(15) (a) Tseng, H.-R.; Luh, T.-Y. J. Org. Chem. 1996, 61, 8685. (b) Tseng, H.-R.; Luh, T.-Y. J. Org. Chem. 1997, 62, 4568. (c) Tseng, H.-R.; Lee, C.-F.; Yang, L.-M.; Luh, T.-Y. J. Org. Chem. 1999, 64, 8582.

(16) (a) Lee, C.-F.; Yang, L.-M.; Hwu, T.-Y.; Feng, A.-H.; Tseng, J.C.; Luh, T.-Y. J. Am. Chem. Soc. 2000, 122, 4992. (b) Zhang, L.-Z.; Chen, C.-W.; Lee, C.-F.; Wu, C.-C.; Luh, T.-Y. Chem. Commun. 2002, 2336. (c) Lee, C.-F.; Liu, C.-Y.; Song, H.-C.; Luo, S.-J.; Tseng, J.-C.; Tso, H.-H.; Luh, T.-Y. Chem. Commun. 2002, 2824. (d) Liu, C.-Y.; Luh, T.-Y. Org. Lett. 2002, 4, 4305. (e) Chou, C.-M.; Chen, W.-Q.; Chen, J.-H.; Tseng, J.-C.; Lee, C.-F.; Luh, T.-Y. Chem. Asian J. 2006, 1-2, 46. (f) Tseng, J.-C.; Chen, J.-H.; Luh, T.-Y. Synlett. 2006, 1209.

(17) (a) For a recent review, see: Fürstner, A.; Martin, R. Chem. Lett. 2005, 34, 624. (b) Nakamura, M.; Matsuo, K.; Ito, S.; Nakamura, E. J. Am. Chem. Soc. 2004, 126, 3686. (c) Nagano, T.; Hayashi, T. Org. Lett. 2004, 6, 1297. (d) Beford, R. B.; Bruce, D. W.; Frost, R. M.; Goodby, J. W.; Hird, M. Chem. Commun. 2004, 2822. (e) Dunet, G.; Knochel, P. Synlett 2006, 407. (f) Dongol, K. G.; Koh, H.; Sau, M.; Chai, C. L. L. Adv. Synth. Catal. 2007, 349, 1015.

(18) (a) Cardellicchio, C.; Fiandanese, V.; Marchese, G.; Ronzini, L. Tetrahedron Lett. 1985, 26, 3595. (b) Fiandanese, V.; Marchese, G.; Naso, F. Tetrahedron Lett. 1988, 29, 3587. (c) Itami, K.; Higashi, S.; Mineno, M.; Yoshida, J.-i. Org. Lett. 2005, 7, 1219.

(19) (a) Alper, H.; Prince, T. L. Angew. Chem., Int. Ed. 1980, 19, 315. (b) Alper, H.; Ripley, S.; Prince, T. L. J. Org. Chem. 1983, 48, 250. (c) Alper, H.; Sibtain, F.; Haveling, J. Tetrahedron Lett. 1985, 24, 5329.

(20) An excess amount of MeMgI (5 equiv) was necessary in order to drive the reaction to completeness.
Table 1. Olefination of Benzylic Dithioacetals 1
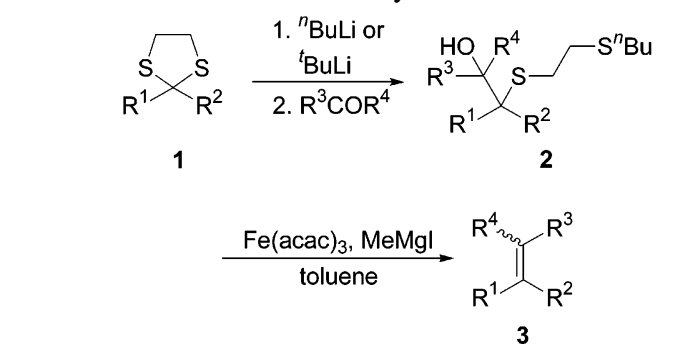

\begin{tabular}{|c|c|c|c|c|c|c|}
\hline & $\mathrm{R}^{1}$ & $\mathrm{R}^{2}$ & $\mathrm{R}^{3}$ & $\mathrm{R}^{4}$ & $\begin{array}{c}\% \text { yield of } 2 \\
\text { (dr ratio) }\end{array}$ & $\%$ yield of 3 \\
\hline $\mathbf{a}$ & $\mathrm{Ph}$ & $\mathrm{Ph}$ & $\mathrm{H}$ & $\mathrm{H}$ & 79 & 63 \\
\hline b & & & $\mathrm{Me}$ & $\mathrm{H}$ & 90 & 82 \\
\hline c & & & $\mathrm{Ph}$ & $\mathrm{H}$ & 61 & 72 \\
\hline d & & & $4-\mathrm{MeOC}_{6} \mathrm{H}_{4}$ & $\mathrm{H}$ & 87 & 84 \\
\hline $\mathbf{e}$ & $\mathrm{Ph}$ & $\mathrm{Me}$ & $\mathrm{PhCH}=\mathrm{CH}-$ & $\mathrm{H}$ & $78(3.0 / 1)$ & $75^{a}$ \\
\hline $\mathbf{f}$ & & & $-\mathrm{C}_{5} \mathrm{H}_{10}-$ & & 88 & 63 \\
\hline $\mathbf{g}$ & $\mathrm{Ph}$ & $\mathrm{H}$ & $\mathrm{PhCH}=\mathrm{CH}$ & $\mathrm{H}$ & $83^{b}(2.0 / 1)$ & 53 \\
\hline
\end{tabular}

${ }^{a} E / Z=6 / 1 . E$ isomer was obtained after recrystalization from etherpentane. ${ }^{b t} \mathrm{BuLi}$ was used.

We have previously shown that aryl-substituted propargylic dithioacetals 4 react with ${ }^{n}$ BuLi followed by treatment with an aldehyde afforded regioselectively allenyl carbinols 5 which undergo cyclization upon treatment with trifluoroacetic acid to give corresponding trisubstituted furans $\mathbf{6}$ (eq 2)..$^{14,16}$

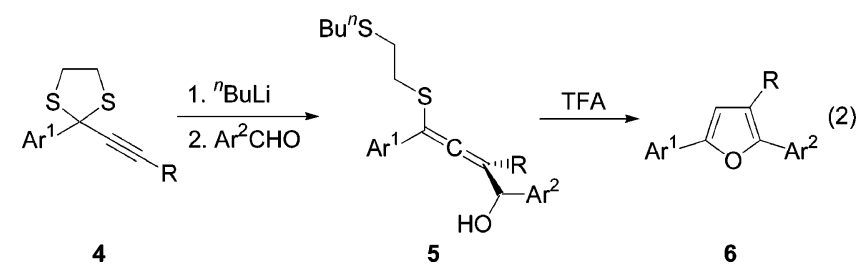

Strikingly, when an alkyl-substituted propargylic dithioacetal $7^{21}$ was employed, homopropargylic alcohol 8 was obtained exclusively in good yield (eq 3). No allenylmethanol derivatives like $\mathbf{5}$ were detected from the crude reaction mixture. Typical results are summarized in Table 2. It is worthy to mention that a range of carbonyl electrophiles can be used in this coupling reaction. However, longer reaction time (e.g., $8 \mathrm{~h}$ ) was necessary for the reactions with a bulky aldehyde (e.g., 8d). The discrepancy in selectivity of the reaction with $\mathbf{4}$ and with $\mathbf{7}$ is unexpected.

Subsequent treatment of $\mathbf{8}$ with 1 equiv of $\mathrm{Fe}(\mathrm{acac})_{3}$ and 5 equiv of $\mathrm{MeMgI}$ afforded the corresponding enynes 9 in

(21) The aliphatic-substituted propargylic dithioacetals 7 were conveniently obtained from the alkylation of the anion of the corresponding parent dithioacetals 10 (cf. Huang, L.-F.; Lee, C.-F.; Tseng, J.-C.; Luh, T.-Y. Synlett 2006, 3173). The details are described in the Supporting Information.

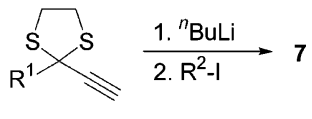

10 
Table 2. Enynes 9 from Propargylic Dithioacetals 7

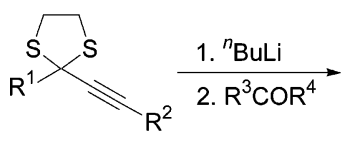

7

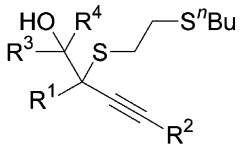

8

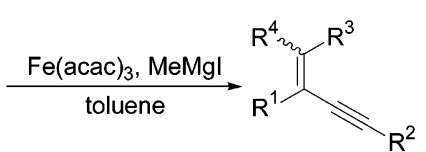

9

\begin{tabular}{|c|c|c|c|c|c|c|}
\hline & $\mathrm{R}^{1}$ & $\mathrm{R}^{2}$ & $\mathrm{R}^{3}$ & $\mathrm{R}^{4}$ & $\begin{array}{l}\% \text { yield of } 8 \\
\text { (dr ratio) }\end{array}$ & $\begin{array}{l}\% \text { yield of } \\
\mathbf{9}(Z / E)^{b}\end{array}$ \\
\hline $\mathbf{a}$ & $\mathrm{Cy}$ & ${ }^{n} \mathrm{Bu}$ & ${ }^{i} \operatorname{Pr}$ & $\mathrm{H}$ & $88^{a}$ & $73(32 / 1)^{c}$ \\
\hline b & & & $\mathrm{Ph}$ & $\mathrm{H}$ & $79(6.1 / 1)$ & $62(22 / 1)$ \\
\hline c & & & $\mathrm{Me}$ & $\mathrm{Me}$ & 89 & 78 \\
\hline d & ${ }^{i} \mathrm{Pr}$ & ${ }^{n} \mathrm{Bu}$ & 1-Ad & $\mathrm{H}$ & $73(3.1 / 1)$ & $62^{d}$ \\
\hline $\mathbf{e}$ & ${ }^{i} \mathrm{Pr}$ & TMS & $\mathrm{Ph}$ & $\mathrm{H}$ & $84(7.1 / 1)$ & $74(20 / 1)$ \\
\hline $\mathbf{f}$ & ${ }^{n} \mathrm{Bu}$ & ${ }^{n} \mathrm{Bu}$ & $\mathrm{Ph}$ & $\mathrm{H}$ & $81(2.9 / 1)$ & $63(10 / 1)$ \\
\hline $\mathbf{g}$ & & & $\mathrm{PhCH}=\mathrm{CH}$ & $\mathrm{H}$ & $81(2.5 / 1)$ & $77^{d}$ \\
\hline
\end{tabular}

${ }^{a}$ Ratios are difficult to determine because of overlapping signals for major and minor isomers. ${ }^{b}$ Stereochemistry was assigned by NOE experiments. ${ }^{c}$ Products decomposed upon standing at rt. ${ }^{d}$ A single diastereomer was obtained.

good yield (Table 2). The reaction in general was stereoselective, Z-olefins being obtained as the major or the predominant products when the secondary alcohols $\mathbf{8}$ were employed. When propargylic ketone $\mathbf{1 1}$ was used, endiyne 9h was obtained in 52\% yield (eq 4).<smiles>CC(C)C1(C#CCBr)SCCS1</smiles>

$7 b$

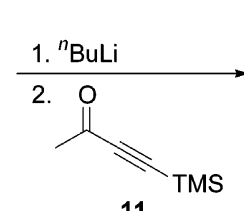

11

$79 \%(12 / 1)$

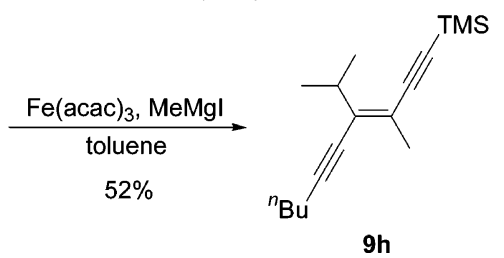

9h

Reaction of allylic dithioacetal $\mathbf{1 2}$ under the same conditions afforded a mixture of diastereomers $13(\mathrm{dr}=5 / 1)(\mathrm{eq}$ 5). Aliphatic substrates, however, underwent different kinds of ring-opening processes to give a mixture of products. ${ }^{22}$

It is known that homopropargylic alcohols may react with $\mathrm{MeMgI}$ in the presence of $\mathrm{Fe}(\mathrm{acac})_{3}$ to give the correspond-

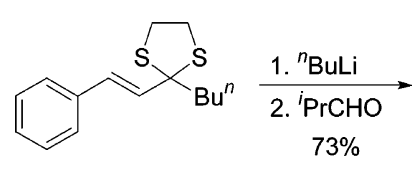

12

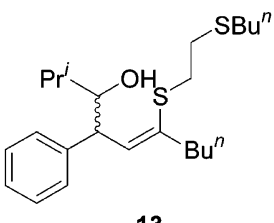

13 ing methylated products. ${ }^{23}$ As shown in Table 2, none of methylated products were formed under these reaction conditions. Although the actual mode of the iron-promoted olefination is not clear at this stage, the benzylic or propargylic carbon-sulfur bond may react preferentially with low valent iron reagent. Elimination of the $\beta$-oxygen moiety might then take place to give the corresponding olefin. Presumably, this oxygen species might bond to iron and the low valent iron cannot be regenerated under the reaction conditions. Indeed, attempts to use subequivalent of Fe(acac) 3 for this transformation gave low yield of product. The high stereoselectivity in the olefination process might be attributed to an equilibrated intermediate $\mathbf{1 4}$ (eq 6) which would lead to a thermodymically more stable Z-olefin.

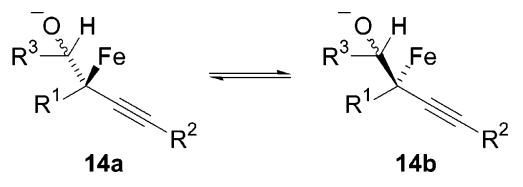

In summary, we have demonstrated a new olefination reaction by coupling of a carbonyl compound with a dithioacetal. A range of substituted alkenes and enynes can be readily obtained by this protocol. The reaction can be considered as an alternative of McMurry-type coupling of two different carbonyl equivalents to give the corresponding olefins. The in situ generated low valent iron reagent may serve as a useful reagent for the activation of carbon-sulfur bonds and for the elimiation of $\beta$-thioalkoxy alcohols.

Acknowledgment. We thank the National Science Council and the National Taiwan University of the Republic of China for financial support.

Supporting Information Available: Experimental details for the synthesis of starting materials 7 and $\mathrm{Fe}(\mathrm{acac})_{3}$ promoted olefination reactions. This material is available free of charge via the Internet at http://pubs.acs.org.

\section{OL701579F}

(22) Wilson, S. R.; Georgiadis, G. M.; Khatri, H. N.; Bartmess, J. E. J. Am. Chem. Soc. 1980, 102, 3577.

(23) Zhang, D.; Ready, J. M. J. Am. Chem. Soc. 2006, 128, 15050. 